Law : Ibid., October, 1877, p. 477. Alexeeff: Archiv. f. Gyn., vol. ix., p. 437. Worthington: Brit. Med. Jour., Jan. 29th, 1876. Nelson: Edinburgh Medical Journal, July, 1877, p. 43. Prince: The LanceT, 1876, vol. i., No. 3. Fischer: Zeitschrift f. Wundärtze und Geburtshülfe, vol. xxviii., part 2. Haultcoeur: Gazette Obstétricale, No. 16, 1874. Sinclair and Johnston: Practical Midwifery, 1858, p. 517. Kiwisch: Klinische Vorträge (fourth edition), p. 275. McClintock: Dublin Quarterly Journal of Medical Science, vol. xxiv., 1858. Williams: Obstetrical Journal of Great Britain, May, 1878, p. 93. Dohrn: Archiv. f. Gynäkologie, vol. iii., p. 492. Watson: Brit. Med. Jour., 1885, vol. ii., p. 699. Hunter: Brit. Med. Jour., 1885, vol. ii., p. 791. Miller: Brit. Med. Jour., 1885, vol. ii., p. 1108. Hubbard; Brit. Med. Jour., 1881, vol. ii., p. 897. Croydon.

\section{ON ACUTE FOLLICULAR TONSILLITIS}

\section{BY ANDREW DUNLOP, M.D.}

CONSULTING PHYSICIAN TO THE JERSEY GGNERAL DISPENSARY.

Tноugh follicular tonsillitis is well known as a throat affection, yet the history and characteristics of an acute form of the disease have not been quite clearly pointed out, and in consequence it does not seem to have been accorded its proper place in our nosology. Notwithstanding, the disease is an interesting one, both on account of its frequent prevalence as an epidemic, and of its apparent relationship to diphtheria. In typical cases the attack is ushered in by malaise and rigors, accompanied with, or, what is more usual, followed by sore-throat, which generally sets in about twenty-four hours after the beginning of the illness. If the throat is examined soon after soreness has been first felt, the tonsils are found to be reddened and somewhat swollen; they may be still free from any excessive secretion, or on one or both of them two or three rounded, yellowish-white spots may be seen-the orifices of folliclesfilled with a material closely resembling cream cheese in colour and consistence. Probably a swollen gland is observed under the angle of the jaw on one or perhaps on both sides; the tongue is generally furred, the appetite is not good, and there is general malaise. In slight cases there is little or no fever, but sometimes the temperature rises to over $102^{\circ}$. On the third day in many cases the symptoms are on the decline; while in others which are more marked both tonsils are now showing yellowish-white spots, and perhaps some of the secretion has escaped from the follicles and spread itself over the tonsil. There may be increased swelling of the glands below the angle of the jaw, only one gland on each, however, being in general affected. With the subsidence of the disease on the third or fourth day the temperature falls to normal, and the secretion on the tonsils disappears more or less abruptly. Some swelling and redness is still left, but this gradually fades away, and the throat has recovered its normal appearance well before the end of the week. In many cases there is stuffiness in the nose, with a little discharge, which is often sanious, and sometimes there is some amount of bleeding. This sketch is an endeavour to depict an average case ; but it is to be remembered that there are some which present few constitutional symptoms, while, on the other hand, there are others which are unusually severe and prolonged. I have seen the temperature rise to $104^{\circ}$, and occasionally there is marked fetor of the breath with considerable swelling of the glands. Some years ago I saw a case in which the throat affection was severe, with great glandular enlargement, and where, soon after convalescence had set in, acute nephritis occurred. There was a question here of the case being one of scarlet fever in which the eruption had been overlooked; but follicular tonsillitis was prevalent at the time, and several other members of the family were suffering from the disease, and also the patient had suffered from a slight attack of scarlatina the previous year.

When a case of follicular tonsillitis is seen where one or both tonsils are covered, or partly covered, with secretion, the resemblance it bears to one of true diphtheria is often very striking. Sometimes the matter acquires an ashy grey tint, which makes it look very like diphtheritic exudation.
It will be found, however, that the friable material, so different from tough membrane, can be easily scraped away.

Acute follicular tonsillitis very frequently, in fact, according to my experience, generally, appears in an epidemic form-that is to say, it is found from time to time occurring in a number of houses scattered over a certain area, and in those houses several members of the same family are usually affected. Sometimes isolated house epidemics are observed, but more commonly the disease appears to take the ordinary epidemic form. It is therefore highly probable that it is infectious, but I have not yet been able to decide whether its prevalence during an epidemic was due to spread by contagion, or whether it was the result of some general cause acting upon the health of the inhabitants of the locality in which it occurred. Its spread has sometimes been apparently favoured by bad sanitary conditions. In one or two houses where during an epidemic a large proportion of the inhabitants were affected I have found defective drainage arrangements which allowed sewer gas to find its way into one or more of the rooms. In other instances, however, no such apparent cause could be detected. Though the disease is clearly distinct from diphtheria, in so far as regards the exudation at least, yet it seems to be closely allied to it. At the end of last year, during an epidemic of acute follicular tonsillitis, there was a considerable number of cases of diphtheria, a disease remarkably rare in Jersey; and, moreover, the cases of diphtheria, so far as I know, were chiefly in a quarter of the town of St. Helier's where follicular tonsillitis was most prevalent. In one family in this part of the town I attended two children suffering from diphtheria, and before they had recovered, their aunt, living in the same house, had a well-marked attack of follicular tonsillitis. In epidemics of diphtheria simple tonsillitis has been noticed to be associated with, and apparently merging into, membranous inflammation and $\mathrm{Mr}$. Hood, in an excellent paper, ${ }^{1}$ also mentions the fact of "tonsillitis of follicular character being found in several instances in which the cause was undoubtedly diphtheria." Moreover, he tells us that "one of the nurses of the West London Hospital had a mild attack of so-called follicular tonsillitis. The throat mischief speedily improved, but a few days later symptoms of paralysis appeared and disclosed the initial attack to have been diphtheria." This case, if it does not prove that the initial attack was diphtheria, at least shows that follicular tonsillitis is very closely allied to it.

I have now seen a good many epidemics of acute follicular tonsillitis, in all of which the disease presented much the same symptoms and characteristics, and followed the same course. It is therefore a question whether it does not merit recognition as a distinct form of specific disease. It appears probable, however, that it is nearly related to diphtheria, much as if it were another species of the same genus. Jersey.

\section{FORM OF EAR AS A SIGN OF DEFECTIVE DEVELOPMENT.}

BY FRANCIS WARNER, M.D. LoND., F.R.C.P., PHYSICIAN TO THE LONDON HOSPITAL.

IN a carefully compiled paper on the ear in criminals, contributed to THE LANCET of Jan. 25th by Mr. H. Havelock Ellis, we have an interesting résumé of the literature of the subject. Attention having thus been directed to the significance of ear defects, it may be worth while to give the results of my own observations.

In connexion with the work of a scientific committee appointed to investigate the condition of children in schools last year, I examined 5344 pupils in primary schools. ${ }^{2}$ of this number of pupils, there were in ten public elementary schools 3931 (boys, 1944; girls, 1987); in four special schools 1413 (boys, 850 ; girls, 563). These special schools were a large pauper school, two certified industrial schools, and a school for the deaf and dumb.

1 THE LANCET, Jan. 12th and 19th, 1889

2 See "Report on Investigation of Condition of School Chlldren." Cambridge University Press. 
In all cases the external ears were looked at, they were found defective in 81 pupils (boys, 49 ; girls, 32)-total number of pupils 1.5 per cent. : boys, 2.5 per cent. ; girls, 1.6 per cent.

This shows that defect of ear is more common in boys than girls. This unequal distribution of congenital defects between the sexes appears to be a general law. The relation of ear defects to criminality must depend upon some correlation of form of ear and make of brain.

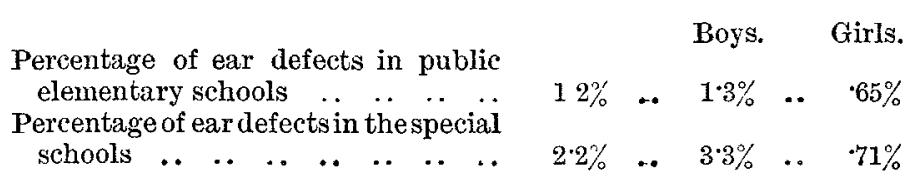

The high percentage of ear defects in the special schools is coincident with signs of low cerebral development as indicated by the following figures:-

\section{Signs of nerve weakness or defect.}

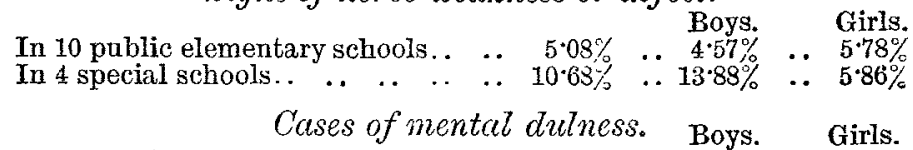

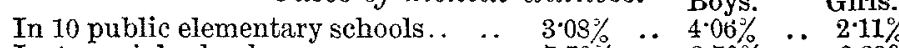

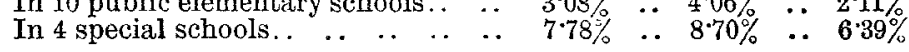

Cranial abnomatities. Boys. Girls.

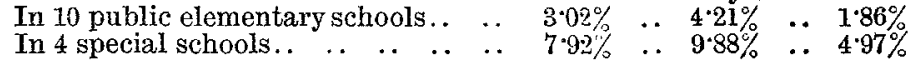

The correlation of defect of ears and other parts in rela. tion with nutrition, mental dulness, and nerve defects is exhibited in the annexed table :-

Conditions of Defective Development of the Ear in relation with Low Nutrition, Mental Dulness, and Nerve Defects. ${ }^{*}$

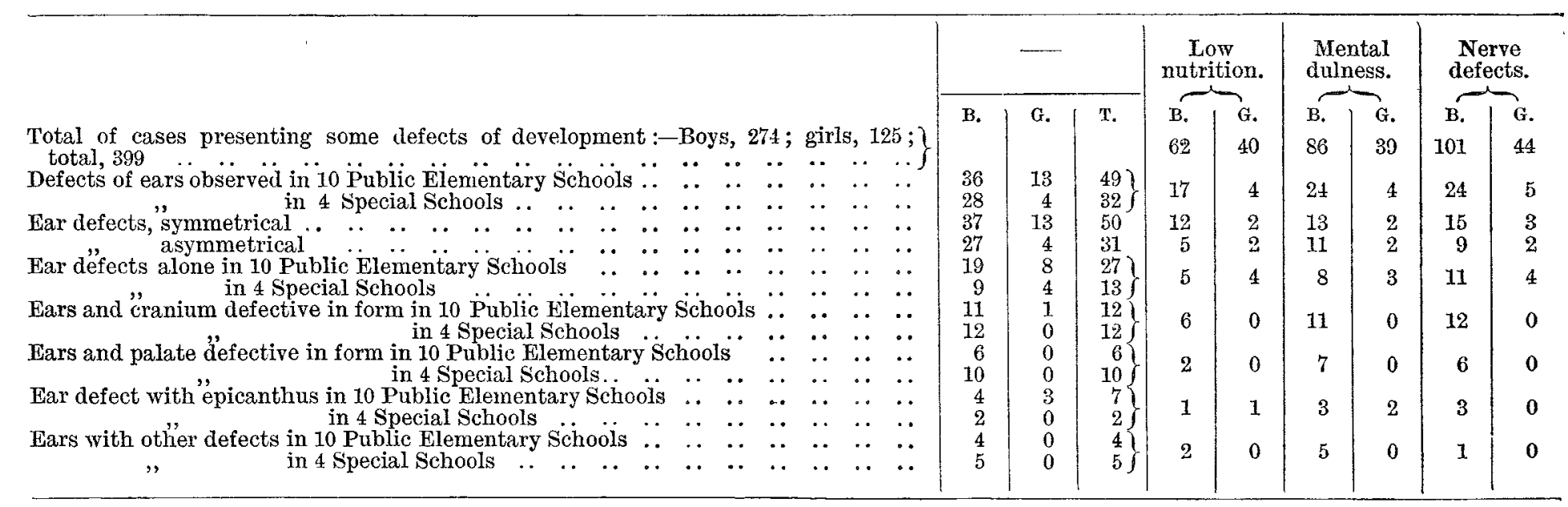

* This analysis is from the 5344 children.

The figures here given tend to show that the defects of the external ears are worthy of clinical observation when seeking evidence as to signs of high class or low development. I have taken this special point, from the observa- tions referred to, as supporting the purport of Mr. Ellis's paper. As a single sign indicative of development I think the form of the palate far more distinctive.

Prince of Wales'-terrace, $W$.

\section{Clinitall âdotes: \\ MEDICAL, SURGICAL, OBSTETRICAL, AND THERAPEUTICAL.}

\section{NERVE STORMS.}

By E. Long Fox, M.D. Oxon., F.R.C.P.Lond.

IN The LANceT of Jan, 25th Dr. Buzzard published a most interesting paper on what is practically a nerve storm affecting the medulla oblongata, and especially the vagus nucleus. I venture to submit short notes of three of the most marked cases of this affection I have lately seen. Although in these cases gout existed, or a gouty family history, it is probable that this is not invariably the exciting cause; and further illustrative cases will be of great interest as bearing on this question. I have considered this condition to be epilepsy of the medulla oblongata; but of course this is only a convenient expression, and in no way an explanation. Some of these cases simulate so closely the gastric crises of tabes dorsalis that it is well always to test the knee-jerks. These have been normal in the cases $I$ have seen.

CASE 1.-A gentleman, aged sixty-two, of gouty history. Ten days ago, on a very cold day, he was upset by a bad smell of sewage; was taken with severe pain in the bowels, with vomiting, and hiccough, but no diarrlica. On the next day the urine was scanty, and contained a good deal of sugar and albumen. The temperature was subnormal. When seen by me, ten days after the commencement of the attack, the sugar and albumen had not reappeared. There was distension of the stomach and bowels. Rejection of food still went on occasionally. Very weak pulse. He was so far recovering from the nerve storn that he would have got well altogether but that he had a weak dilated heart, showing a soft bruit with both sounds at the lower end of the sternum, reaching three inches up the middle line. This previous organic injury rendered the morbid influence on the vagus nucleus fatal in a few days. In this case tinnitus, though it existed, was not a prominent symptom.

CASE 2.-A gentleman aged forty-two. Thin, spare, fairly active, of completely good habits; gouty family history. He has been a fairly busy man. For many years, quite twenty, at variable intervals, and without any warning the night before, he awakes in the morning sometimes with headache, always with pain in the eyeballs and vertigo, and has spent the whole day in attacks of vomiting, with more or less diarrhoea. I have known him have twenty-eight attacks of vomiting in the day. There is no disturbance of the tongue; no appearance of disorder of the stomach or liver. After a good night he will be perfectly well the next day. The attacks are exceedingly like epilepsy affecting an unusual region.

CASE 3.-A lady aged sixty-three. Rather gouty. For the last year she has been subject to nerve storms, apparently affecting the medulla oblongata. Lesser attacks of a similar nature, however, have disturbed her for some years past. The symptoms are: Very frequent booming in the head, not, she says, in the ears; some vertigo; no deafness; great sense of syncope (the beats of the heart remaining regular during the attack, though weak); intense vomiting and diarrhoa. She thinks she is going to die when she gets an attack. No loss of consciousness. I am told that she was once treated for several months with every kind of remedy for dyspepsia, without result; and she is relieved by small doses of bromide of potassium.

Clifton. 